\title{
Extrahepatic Obstructive Cholestasis Reverses the Bile Salt Secretory Polarity of Rat Hepatocytes
}

\author{
Gert Fricker, Lukas Landmann," and Peter J. Meier \\ Division of Clinical Pharmacology, Department of Medicine, University Hospital, CH-8091 Zurich; \\ and *Department of Anatomy, University of Basel, CH-4056 Basel, Switzerland
}

\begin{abstract}
To elucidate the consequences of extrahepatic cholestasis on the structure and function of hepatocytes, we studied the effects of bile duct ligation on the turnover, surface distribution, and functional activity of the canalicular 100-kD bile salt transport protein (cBSTP). Basolateral (blLPM) and canalicular (cLPM) liver plasma membrane vesicles were purified to the same degree from normal and cholestatic rat livers and the membrane bound CBSTP identified and quantitated using polyclonal anti-cBSTP antibodies. Cholestasis of $50 \mathrm{~h}$ resulted in an increased release of cBSTP into bile, thereby decreasing its in vivo half-life from 65 to 25 h. Furthermore, a significant portion of CBSTP accumulated at the basolateral surface and in intracellular vesicles of cholestatic hepatocytes. This redistribution of cBSTP was functionally paralleled by decreased and increased electrogenic taurocholate anion transport in cLPM and blLPM vesicles, respectively. These results demonstrate that biliary obstruction causes a reversal of the bile salt secretory polarity of rat hepatocytes. The resulting increase in basolateral (sinusoidal) bile salt efflux might protect hepatocytes from too high an accumulation of toxic bile salts within the cell interior.
\end{abstract}

\section{Introduction}

Mechanical obstruction of extrahepatic bile ducts results in increased biliary pressure, failure of canalicular bile flow on the level of hepatocytes, and accumulation of obligatory cholephilic compounds such as bile salts, bilirubin, and cholesterol within liver cells and blood plasma. In hepatocytes the most prominent pathologic alterations are initially seen at the excretory pole and include dilatation of bile canaliculi, reduction and loss of canalicular microvilli, and disorganization and increased permeability of the tight junctional complexes (1-4). However, using experimental bile duct ligation, an unambiguous animal model for extrahepatic mechanical obstruction in humans, numerous studies have shown that obstructive chole-

Part of this work was presented at the 38th Annual Meeting of the American Association for the Study of Liver Diseases, Chicago, 27 and 28 October 1987, and has been published in abstract form (1987. Hepatology [Baltimore]. 7: 1106).

Address reprint requests to Dr. Meier, Division of Clinical Pharmacology, Department of Medicine, University Hospital, Rämistrasse 100 CH-8091 Zurich, Switzerland.

Received for publication 24 May 1988 and in revised form 4 May 1989.

J. Clin. Invest.

(c) The American Society for Clinical Investigation, Inc. 0021-9738/89/09/0876/10 \$2.00

Volume 84, September 1989, 876-885 stasis affects many other parts of liver cells as well. For example, the amounts of Golgi complex and of smooth and rough endoplasmic reticulum are decreased while the number of peroxisomes, pericanalicular vesicles, and lysosomes as well as the thickness of the pericanalicular microfilamentous web are increased $(2,3,5)$. Especially intriguing is the observation of retrograde vesicle-mediated transport from bile to blood for lipoprotein X (6) and for dimeric IgA (7), suggesting that retrograde passage via the transcellular route might represent an important pathway for "regurgitation" of bile constituents into blood plasma. Such retrograde diacytosis might also be involved, at least in part, in the described topographic shift of some histochemically demonstrable enzymes (8-10) and antigens (11) from the canalicular to the basolateral (sinusoidal and lateral) membrane domain. Although these findings have been interpreted to reflect a "reversed secretory polarity" in cholestatic hepatocytes $(2,7)$, direct structural and functional proof for this hypothesis has so far not been obtained. Therefore, we investigated the turnover, surface distribution, and functional activity of the recently characterized canalicular bile salt transport protein (cBSTP) ${ }^{1}$ in intact liver and in basolateral (blLPM) and canalicular (cLPM) liver plasma membrane (LPM) vesicles isolated from normal and bile duct-ligated rats (12-16). The results demonstrate an increased release of cBSTP into bile of obstructed animals. Furthermore, a significant portion of functionally active cBSTP accumulated within the basolateral membrane of cholestatic hepatocytes, thus providing direct evidence for reversal of the bile salt secretory polarity of hepatocytes during obstructive cholestasis.

\section{Methods}

Materials. L- $\left[{ }^{35} \mathrm{~S}\right]$ Methionine $(1,060 \mathrm{Ci} / \mathrm{mmol})$ was obtained from Amersham International (Buckinghamshire, UK). [6- $\left.{ }^{3} \mathrm{H}\right]-$ Taurocholate $(6.6 \mathrm{Ci} / \mathrm{mmol})$ was purchased from Du Pont-New England Nuclear (Boston, MA). Protein A-Sepharose CL-4B was from Pharmacia-Schweiz AG (Dübendorf, Switzerland). Nitrocellulose sheets, horseradish peroxidase-conjugated goat anti-rabbit IgG and the horseradish peroxidase color development reagent containing 4chloro-l-naphthol and Bradford color-reagent were from Bio-Rad Laboratories AG (Glattbrugg, Switzerland). Newborn calf serum was from Sera-Lab (Sussex, England). All other chemicals and reagents were of analytical grade and were readily available from commercial sources.

Animals. Male Sprague-Dawley rats (SUT:STD, Süddeutsches Tierzuchtinstitut, Tuttlingen, Federal Republic of Germany) weighing 200-250 $\mathrm{g}$ were used throughout this study. The animals had free access to water, were fed ad lib. (na. 690 diet, Nafag, Gossau, Switzerland) and housed in a constant temperature and humidity environ-

1. Abbreviations used in this paper: blLPM, basolateral liver plasma membranes; cLPM, canalicular liver plasma membranes; cBSTP, canalicular bile salt transport protein; RE, relative enrichment; LPM, liver plasma membranes. 
ment with alternating 12-h light (6:30 a.m. to 6:30 p.m.) and dark cycles.

Extrahepatic obstruction was produced by bile duct ligation under pentobarbital (sodium salt, $50 \mathrm{mg} / \mathrm{kg}$ intraperitoneally) anesthesia. The common bile duct was ligated close to the liver hilus to prevent damage to pancreatic ducts. Sham-operated animals were handled in a similar manner without ligation of the bile duct. Both groups of animals were allowed to eat ad lib. after surgery. After various postoperative periodes (maximal $72 \mathrm{~h}$ ) rats were regularly killed by cervical dislocation at 8:00 a.m.

Isolation of LPM subfractions. Essentially the same procedure was used for isolation of mixed LPM, blLPM, and cLPM subfractions as previously described (17). However, the reported high-yield, zonal centrifugation procedure (17) had to be scaled down and adapted to one to three rat livers in order to permit the parallel isolation of LPM subfractions from sham-operated and bile duct-ligated animals at the same day. In addition, the simultaneous preparation of mixed LPM from up to six livers was necessary for determination of the half-life of the 100-kD bile salt transport polypeptide (Fig. 1). Therefore, 10-30-g liver portions from differently treated animals were separately homog-

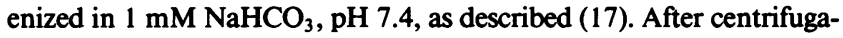
tion at $1,500 \mathrm{~g}_{\mathrm{ave}}$ for $15 \mathrm{~min}$ (GSA rotor, Du Pont Instruments, Sorvall Biomedical Div., Newtown, CT), each crude nuclear pellet originating from one rat liver $(\sim 10 \mathrm{~g})$ was resuspended in 2.2 vol of $70 \%$ sucrose (wt/wt, $d 1.2623$ ) to a final volume of $\sim 40 \mathrm{ml}$. The suspensions were stirred on ice for $10 \mathrm{~min}$ to disrupt membrane aggregations. 15-ml samples of each diluted crude nuclear suspension were then overlaid with $12 \mathrm{ml}$ of $44 \%$ sucrose (wt/wt, $d 1.1972$ ) followed by $10 \mathrm{ml}$ of $36.5 \%$ sucrose (wt/wt, $d 1.1587$ ), and the centrifuge tubes (Ultra-Clear, $25 \times 89 \mathrm{~mm}$, Beckman Instruments, Inc., Palo Alto, CA) were filled to

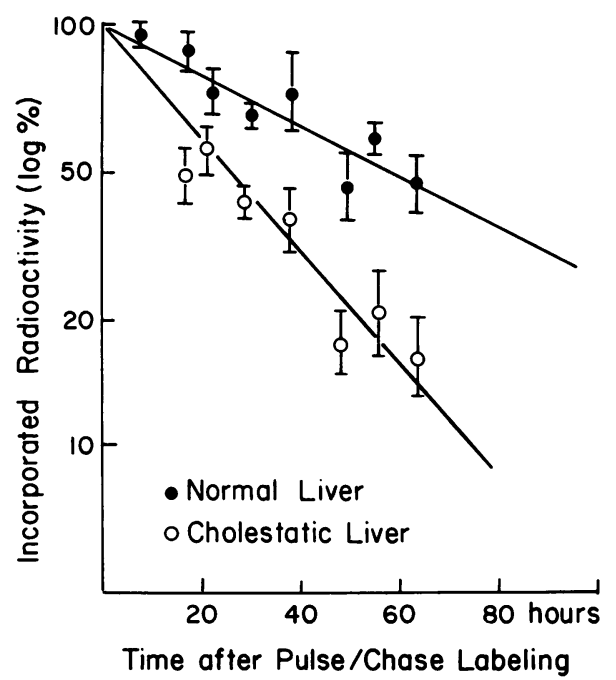

Figure 1. Degradation half-life of membrane bound cBSTP in normal and cholestatic rat liver. Rats were pulse-labeled with L- $\left[{ }^{35} S\right]-$ methionine $(0.5 \mathrm{mCi}$ intraperitoneally) and chases of unlabeled methionine ( $50 \mathrm{mg}$ intraperitoneally) administered after $2 \mathrm{~h}$ and subsequently at 12 -h intervals. $12 \mathrm{~h}$ after pulse-labeling the animals were sham-operated (๑) or subjected to bile duct ligation (0). After the indicated time intervals (zero time = pulse-labeling), mixed LPM fractions were isolated and membrane-bound cBSTP quantitatively immunoprecipitated from solubilized LPM extracts. The radioactivity in immunoprecipitates was determined by liquid scintillation counting. Three animals corresponding to different postoperative periods were processed in parallel with the appropriate controls at the same day. Each illustrated time point represents the means \pm SD of three independent experiments. Individual points were fitted by linear regression analysis and the lines extrapolated back to $100 \%$ incorporated radioactivity. Note the logarithmic scale of the ordinate. the top with $0.25 \mathrm{M}$ sucrose. The discontinuous sucrose gradients were centrifuged at $95,000 \mathrm{~g}_{\text {ave }}$ for $150 \mathrm{~min}$ (AH 627 swing-out rotor, Du Pont Instruments, Sorvall Biomedical Div.). After centrifugation mixed LPMs were recovered from the $36.5 \% / 44 \%$ sucrose interface, washed twice in $40 \mathrm{ml}$ of $1 \mathrm{mM} \mathrm{NaHCO}$, and finally collected at $2,700 g_{\text {ave }}$ for $15 \mathrm{~min}$. Subsequent separation of blLPM and cLPM subfractions from the mixed LPM was exactly as described (17). This modified isolation procedure permitted to individually process up to six different livers ( $10 \mathrm{~g}$ each) at the same day as required for the half-life studies described below. The isolated LPM subfractions were resuspended in the appropriate buffer media and aliquots were stored frozen in liquid nitrogen (protein concentration $>5 \mathrm{mg} / \mathrm{ml}$ ) for up to 2 wk without loss of transport functions. Protein was determined by the method of Bradford (18) using bovine $\gamma$-globulin as standard.

Enzymatic characterization of isolated LPM subfractions. Frozen samples were quick-thawed immediately before use by immersion of the tubes into a $37^{\circ} \mathrm{C}$ waterbath. The ouabain-sensitive $\mathrm{Na}^{+} \mathrm{K}^{+} \mathrm{ATP}-$ ase and the $\mathrm{Mg}^{2+}$-ATPase activities were determined by the coupled kinetic assay as modified by Scharschmidt et al. (19). Leucineaminopeptidase activity was measured according to Goldbarg and Rutenburg (20). Alkaline phosphatase activity was assayed as described (21) using $p$-nitrophenylphosphate as substrate. $\gamma$-Glutamyltranspeptidase activity was determined according to Orlowski and Meister (22). To test for the presence of intracellular organelles, we measured the following marker enzyme activities: succinate cytochrome $c$ reductase for mitochondria (23), NADPH cytochrome $c$ reductase for microsomes (23), acid phosphatase for lysosomes (24), and galactosyltransferase for Golgi membranes (25).

SDS gel electrophoresis. SDS-PAGE was performed as described (26) using a Mini PROTEAN II dual-slab cell (Bio-Rad Laboratories AG) and a polyacrylamide concentration of $9.5 \%$. The separated polypeptide bands were stained either with Coomassie brilliant blue $\mathbf{R} 250$ (27) or alternatively by the silver stain technique (28).

Antibody preparation against the $100-k D c B S T P$. The same polyclonal rabbit antibodies as previously characterized (15) were used throughout this study.

Immunoblotting and immunoprecipitation procedures. CBSTP was selectively detected in and immunoprecipitated from solubilized LPM subfractions as described (15). In all immunoprecipitation assays quantitative recovery of cBSTP was assessed by immunoblotting of the corresponding supernatants.

Determination of the half-life of membrane-bound cBSTP in vivo. Rats were pulse-labeled by intraperitoneal injection of $0.5 \mathrm{mCi}$ of $\mathrm{L}-\left[{ }^{35} \mathrm{~S}\right]$ methionine in $0.5 \mathrm{ml}$ of PBS. $2 \mathrm{~h}$ later, a chase consisting of 2.5 $\mathrm{ml}$ of $20 \mathrm{mg} / \mathrm{ml}$ unlabeled L-methionine in PBS was administered intraperitoneally, and additional chases $(2.5 \mathrm{ml}$ each) were injected at 12-h intervals. The adequacy of the initial pulse-labeling period was ascertained in separate experiments where maximal incorporation of radioactivity into plasma membrane bound cBSTP was found after 2 h. Furthermore, varying the chase intervals between 8 and $12 \mathrm{~h}$ demonstrated that $12-\mathrm{h}$ periods were sufficient to prevent late incorporation of newly synthesized radioactive cBSTP into LPM subfractions. $12 \mathrm{~h}$ after pulse labeling ( $10 \mathrm{~h}$ after the first chase) the animals were either sham operated (controls), or their bile duct was ligated. After various time intervals (zero time $=$ pulse labeling), the rats were killed, their livers were excised, and mixed LPM were isolated in parallel from six individual livers (see above). cBSTP was quantitatively immunoprecipitated from each mixed LPM preparation. The immunoprecipitates were dissolved in $5 \mathrm{ml}$ of scintillation cocktail (Opti-Fluor, Canberra-Packard International SA, Zurich, Switzerland) and the radioactivity was determined in a liquid scintillation counter (Tri-Carb 460 CD, Canberra-Packard International SA).

Rocket immunoelectrophoresis. The content of membrane-bound CBSTP was quantitatively determined in a total particulate fraction (sedimented from homogenates at $100,000 \mathrm{~g}_{\text {ave }}$ for $30 \mathrm{~min}$ ) and in isolated LPM subfractions from control and cholestatic livers by rocket immunoelectrophoresis (29). The electrophoresis was carried out in a flat-bed apparatus (FBE 3000, Pharmacia/LKB, Dübendorf, Switzer- 
land) using $93 \times 84-\mathrm{mm}$ gel-bond slides that were covered with $1 \%$ agarose in electrophoresis buffer containing $91.5 \mathrm{mM}$ Tris, $30.4 \mathrm{mM}$ diethylbarbituric acid, $4 \mathrm{mM} \mathrm{Ca}^{2+}$-lactate, $2.5 \mathrm{mM} \mathrm{NaN}_{3}, 0.2 \%$ Triton $\mathrm{X}-100,9.7 \mathrm{mM} \mathrm{Na}^{+}$-cholate and $1 \%$ (vol/vol) rabbit anti-cBSTP serum. LPM samples were solubilized in electrophoresis buffer without anti-cBSTP serum, and sample volumes between 2.5-7.5 $\mu \mathrm{l}$ (25-100 $\mu \mathrm{g}$ of protein) were applied into holes punched into the agarose slides 1 $\mathrm{cm}$ apart from the cathodic side. Electrophoresis was performed at $\mathbf{8 0}$ $\mathrm{V}$ for $20 \mathrm{~h}$ at $15^{\circ} \mathrm{C}$. Subsequently the agarose plates were equilibrated with $250 \mathrm{ml}$ PBS for $4 \mathrm{~h}$ to remove nonprecipitated proteins. After drying $\left(20^{\circ} \mathrm{C}\right.$ for $\left.5 \mathrm{~h}\right)$ the plates were stained in $20 \%$ methanol, $7.5 \%$ acetic acid, and $0.25 \%$ Serva Blue S (Serva, Heidelberg, Federal Republic of Germany) for 30 min and destained in $20 \%$ methanol, $7.5 \%$ acetic acid for at least $2 \mathrm{~h}$. The content of cBSTP in the various samples was estimated from the planimetrically determined area under the rocket-shaped precipitation lines.

Immunolocalization of $c B S T P$. For immunofluorescence studies, liver tissue samples were snap frozen in liquid nitrogen. Cryostat sections $(5 \mu \mathrm{m})$ were fixed for $10 \mathrm{~min}$ in cold acetone $\left(0-4^{\circ} \mathrm{C}\right)$ and air dried. After rehydration the sections were sequentially incubated for 20 min at room temperature in each of the following reagents: $(a)$ normal goat serum (1:5 dilution, Miles Scientific, Inc., Naperville, IL), (b) rabbit anti-cBSTP serum (1:100 dilution), and $(c)$ FITC-conjugated goat anti-rabbit serum IgG (1:20 dilution, Miles Scientific, Inc.). All dilutions and rinsing steps between incubations were performed with Tris-buffered saline (pH 7.6). Controls for nonspecific fluorescence were prepared by replacing anti-cBSTP serum with preimmune serum at the same concentration. Slides were coverslipped with glycerol and examined immediately.

For immunogold labeling, livers were perfusion fixed with freshly prepared paraformaldehyde in $0.1 \mathrm{M}$ phosphate buffer, $\mathrm{pH}$ 7.4. Small tissue blocks $(0.5-1 \mathrm{~mm})$ were cryoprotected with $2.3 \mathrm{M}$ sucrose and rapidly frozen in liquid propane. Frozen semithin sections $(1 \mu \mathrm{m})$ were cut on a Reichert FC 4E Ultracut, mounted on chromalum gelatine coated slides, and incubated at room temperature sequentially in $(a)$ normal goat serum (1:50 dilution, $10 \mathrm{~min}$ ), (b) rabbit anti-cBSTP serum (1:500 dilution, $1 \mathrm{~h}$ ), and (c) goat anti-rabbit IgG-coated colloidal gold ( $5 \mathrm{~nm}, 1: 50$ dilution, $1 \mathrm{~h}$, Janssen, Olen, Belgium). All dilutions and rinsing steps were performed with PBS. The gold label was visualized with a silver enhancement kit (IntenSE M, Janssen). Some sections were counterstained with Mayer's hematoxylin. After dehydration slides were coverslipped with Entellan (Merck \& Co., Darmstadt, Federal Republic of Germany). Controls for nonspecific label were prepared by replacing anti-cBSTP serum with preimmune serum or with PBS.

Micrographs were taken with standardized shutter speeds on a Photomicroscope II (Carl Zeiss-Schweiz Inc., Zurich, Switzerland) equipped with epifluorescence illumination using 450-490-nm exciter and 515-565-nm barrier filters in combination with a 510-nm dichromatic beam splitter or on a bright-field microscope (Axiophot, Carl Zeiss, Inc.). Paired prints were exposed for identical time periods.

Vesicle transport studies. Frozen membrane suspensions were quickly thawed by immersion of the tubes in a $37^{\circ} \mathrm{C}$ waterbath, diluted to the desired protein concentration $(2.5-10 \mathrm{mg} / \mathrm{ml})$, revesiculated by 20 passages through a 25 -gauge needle and kept on ice until used. Preloading of cLPM vesicles was performed by adding $\left[{ }^{3} \mathrm{H}\right]-$ taurocholate $(10 \mu \mathrm{M})$ before revesiculation followed by preincubation of the vesicles at $25^{\circ} \mathrm{C}$ for $20 \mathrm{~min}$. Where indicated the vesicles were also treated with valinomycin $(10 \mu \mathrm{g} / \mathrm{mg}$ protein; Figs. 4 and 5$) .\left[{ }^{3} \mathrm{H}\right]-$ taurocholate efflux from cLPM vesicles and tracer uptake into blLPM vesicles were determined by a rapid filtration technique as previously described $(12,13)$. The exact incubation conditions are given in the corresponding figure legends (Figs. 4-6). After the indicated time intervals the reactions were stopped by addition of $2.5 \mathrm{ml}$ of ice-cold stop solution consisting of $100 \mathrm{mM} \mathrm{K}{ }^{+}, 100 \mathrm{mM}$ sucrose, $5 \mathrm{mM} \mathrm{Mg}^{2+}, 0.2$ $\mathrm{mM} \mathrm{Ca}^{2+}, 110.4 \mathrm{mM}$ gluconate, $10 \mathrm{mM}$ Hepes/Tris, $\mathrm{pH}$ 7.5. Vesicleassociated ligand was separated from free ligand by rapid filtration through a $0.45-\mu \mathrm{m}$ nitrocellulose filter (Sartorius, Göttingen, Federal
Republic of Germany) that was preincubated in and additionally prewashed with $1 \mathrm{mM}$ taurocholate $(2 \mathrm{ml})$ to reduce nonspecific filter binding. After two washes with $2.5 \mathrm{ml}$ of cold stop solution, the filters were dissolved in $5 \mathrm{ml}$ of scintillation fluid (Filter Count, CanberraPackard International SA). All measurements were performed in quadruplicates in at least two different membrane preparations.

\section{Results}

Characteristics of cholestatic animals. After $50 \mathrm{~h}$, body weights were similar in sham-operated $(231 \pm 11 \mathrm{~g}$; means $\pm \mathrm{SD}, n=12)$ and bile duct-ligated $(226 \pm 12 \mathrm{~g})$ animals whereas liver weights of bile duct-ligated rats were slightly decreased from $14.3 \pm 1.6$ to $11.6 \pm 1.1 \mathrm{~g}(P<0.01)$, respectively. In serum, bile duct ligation increased the concentrations of bile acids to $48.3 \pm 4.2$ $\mu \mathrm{mol} /$ liter (controls: $2.0 \pm 0.5 \mu \mathrm{mol} / \mathrm{liter}$ ), total bilirubin to 99 $\pm 29 \mu \mathrm{mol} /$ liter (controls: $2.5 \pm 0.8 \mu \mathrm{mol} / \mathrm{liter}$ ), and alkaline phosphatase to $525 \pm 131 \mathrm{U} /$ liter (controls: $354 \pm 70 \mathrm{U} /$ liter). Light and transmission electron microscopy showed qualitatively the well-known alterations (5). The most prominent changes occurred at the secretory pole of hepatocytes including dilatation of bile canaliculi, distortion and reduction of canalicular microvilli, and thickening of the pericanalicular ectoplasma containing numerous vesicles (see Fig. $3 \mathrm{D}$ ).

Enzymatic characterization of LPM subfractions isolated from normal and cholestatic rat liver. For correct interpretation of the vesicle studies outlined below, it was necessary to verify that comparable blLPM and CLPM subfractions could be purified from sham-operated and bile duct-ligated animals. Under both conditions total protein recoveries from $10 \mathrm{~g}$ of liver were identical for blLPM (controls, $3.4 \pm 0.4 \mathrm{mg}, 50 \mathrm{~h}$; bile duct ligation, $3.4 \pm 0.5 \mathrm{mg}$; means $\pm \mathrm{SD}, n=12$ ) whereas those for CLPM were slightly reduced from $2.6 \pm 0.3 \mathrm{mg}$ protein in controls to $1.9 \pm 0.4 \mathrm{mg}$ in bile duct-ligated $(50 \mathrm{~h})$ animals. $\mathrm{Na}^{+} \mathrm{K}^{+}$ATPase activity was slightly, but insignificantly increased in homogenates after $50 \mathrm{~h}$ of bile duct ligation (Table I). However, significant 20-30\% increases of $\mathrm{Na}^{+} \mathrm{K}^{+}$ATPase activity were found in homogenates and mixed LPM at 14 and $26 \mathrm{~h}$ after surgery (data not shown). Based on $\mathrm{Na}^{+} \mathrm{K}^{+}$ATPase activity $(17,30-33)$ and on marker enzyme activities for mitochondria (succinate cytochrome $c$ reductase) lysosomes (acid phosphatase) and Golgi membranes (galactosyltransferase), bile duct ligation for $50 \mathrm{~h}$ did not prevent successful purification and separation of blLPM and CLPM vesicles by sucrosedensity centrifugations (Table I). In addition, contaminations with endoplasmic reticulum membranes (NADPH cytochrome $c$ reductase) were low, although "cholestatic" blLPM were approximately twofold more contaminated with microsomes (relative enrichment [RE] 0.8) compared with "normal" blLPM (RE 0.4; Table I). The most significant differences in enzyme activities were obtained for the canalicular markers $\mathrm{Mg}^{2+}$ ATPase, leucineaminopeptidase, alkaline phosphatase, and $\gamma$-glutamyltranspeptidase (Table I). Alkaline phosphatase activity was 2.2-fold higher in homogenates of cholestatic compared with control livers, which most probably reflects enzyme induction $(34,35)$. Although alkaline phosphatase activity was 1.7 -fold less enriched in cholestatic cLPM vesicles (RE 42 vs. 70 in controls), it still exhibited a $33 \%$ higher absolute specific activity $\left(16.8 \mu \mathrm{mol} \cdot \mathrm{mg}^{-1} \cdot \mathrm{h}^{-1}\right)$ compared with normal $\mathrm{cLPM}\left(12.6 \mu \mathrm{mol} \cdot \mathrm{mg}^{-1} \cdot \mathrm{h}^{-1}\right)$. In contrast, $\mathrm{Mg}^{2+}$ ATPase, leucineaminopeptidase, and $\gamma$-glutamyltranspeptidase activities were significantly decreased in CLPM of 


\begin{tabular}{|c|c|c|c|c|c|c|c|c|}
\hline & & & \multicolumn{6}{|c|}{$(\mathrm{RE})^{8}$} \\
\hline & \multicolumn{2}{|c|}{$\begin{array}{l}\text { Homogenates (specific } \\
\text { activity) }\end{array}$} & \multicolumn{2}{|c|}{ Mixed LPM } & \multicolumn{2}{|c|}{ blLPM } & \multicolumn{2}{|c|}{ cLPM } \\
\hline & Control & Cholestasis & Control & Cholestasis & Control & Cholestasis & Control & Cholestasis \\
\hline $\mathrm{Na}^{+} / \mathrm{K}^{+}$-ATP'ase & $0.66 \pm 0.20$ & $0.82 \pm 0.38$ & $16 \pm 7$ & $12 \pm 5$ & $30 \pm 9$ & $23 \pm 11$ & $2 \pm 0.1$ & $2 \pm 0.2$ \\
\hline $\mathrm{Mg}^{2+}$-ATP'ase & $2.20 \pm 0.70$ & $2.42 \pm 0.44$ & $6 \pm 2$ & $6 \pm 2$ & $6 \pm 2$ & $4 \pm 0.3$ & $46 \pm 10$ & $9 \pm 0.5^{\| \prime}$ \\
\hline Leucineaminopeptidase & $3.50 \pm 0.90$ & $3.21 \pm 1.15$ & $4 \pm 2$ & $1 \pm 0.5$ & $2 \pm 1$ & $2 \pm 0.1$ & $23 \pm 4$ & $13 \pm 0.7^{\| \prime}$ \\
\hline Alkaline phosphatase & $0.18 \pm 0.02$ & $0.40 \pm 0.21$ & $13 \pm 2$ & $18 \pm 5$ & $8 \pm 3$ & $5 \pm 1$ & $70 \pm 15$ & $42 \pm 4^{11}$ \\
\hline$\gamma$-Glutamyltranspeptidase & $0.03 \pm 0.01$ & $0.02 \pm 0.01$ & $6 \pm 2$ & $5 \pm 2$ & $5 \pm 1$ & $5 \pm 2$ & $27 \pm 2$ & $15 \pm 2^{\prime \prime}$ \\
\hline Succinate-cytochrome $c$-reductase & $4.60 \pm 2.10$ & $3.10 \pm 0.60$ & $2.5 \pm 0.7$ & $3.6 \pm 0.5^{\|}$ & $1.5 \pm 0.3$ & $1.7 \pm 0.6$ & $0.2 \pm 0.1$ & $0.2 \pm 0.03$ \\
\hline NADPH-cytochrome $c$-reductase & $1.84 \pm 0.70$ & $1.50 \pm 0.60$ & $0.4 \pm 0.1$ & $0.6 \pm 0.2^{\|}$ & $0.4 \pm 0.1$ & $0.8 \pm 0.1$ & $1.3 \pm 0.2$ & $1.1 \pm 0.2$ \\
\hline Acid phosphatase & $0.41 \pm 0.10$ & $0.40 \pm 0.12$ & $0.8 \pm 0.3$ & $0.9 \pm 0.4$ & $0.4 \pm 0.1$ & $0.4 \pm 0.2$ & $0.8 \pm 0.2$ & $0.7 \pm 0.2$ \\
\hline Galactosyltransferase & $13.2 \pm 5.80$ & $15.0 \pm 4.0$ & $0.2 \pm 0.1$ & $0.3 \pm 0.2$ & ND & ND & ND & ND \\
\hline
\end{tabular}

ND, not detectable. * LPM subfractions were isolated $50 \mathrm{~h}$ after sham operation (controls) or bile duct ligation (cholestasis), respectively. ${ }^{\ddagger}$ All data represent the means \pm SD of single measurements in six separate membrane preparations $(n=6)$. Specific activities are expressed as $\mu \mathrm{mol}$ product formed $\cdot \mathrm{mg}^{-1}$ protein $\cdot \mathrm{h}^{-1}$, except for galactosyltransferase for which the corresponding units are nmol galactose transferred $\cdot \mathrm{mg}^{-1} \cdot \mathrm{h}^{-1}$. ${ }^{\S}$ Relative enrichment $(\mathrm{RE})$ is defined as the ratio of specific activity in the LPM to specific activity in the homogenate. "Significantly different from controls $(P<0.05)$ as determined by paired Student $t$ test.

cholestatic liver by $88 \%, 49 \%$, and $63 \%$, respectively (Table I). Furthermore, as shown in Table II recoveries of canalicular marker enzyme activities were uniformly decreased in cholestatic cLPM, suggesting loss of canalicular membranes either in vitro during subcellular fractionation or in vivo because of bile duct ligation (see below). In blLPM, enrichment and recovery of canalicular marker enzyme activities were either similar (leucineaminopeptidase, $\gamma$-glutamyltranspeptidase) or only slightly decreased $\left(\mathrm{Mg}^{2+} \mathrm{ATPase}\right.$, alkaline phosphatase) in cholestatic compared with control livers (Tables I and II). These data might reflect (but do not prove) some accumulation of canalicular marker enzymes at the basolateral plasma membrane during obstructive cholestasis $(8-10)$ rather than increased contamination of cholestatic blLPM with cLPM, since the protein recovery was similar in both blLPM subfractions (see above). Thus, it is concluded from the data in Tables I and II that with the exception of a slightly higher microsomal contamination of cholestatic blLPM, the degree of purification

Table II. Enzyme Recovery in blLPM and cLPM Subfractions from Normal and Cholestatic Rat Liver*

\begin{tabular}{|c|c|c|c|c|}
\hline & \multicolumn{4}{|c|}{ Recovery ${ }^{\ddagger}$} \\
\hline & \multicolumn{2}{|c|}{ blLPM } & \multicolumn{2}{|c|}{ cLPM } \\
\hline & Control & Cholestasis & Control & Cholestasis \\
\hline & $\%$ & $\%$ & $\%$ & $\%$ \\
\hline $\mathrm{Na}^{+} \mathrm{K}^{+}$-ATPase & $8.0 \pm 0.8$ & $6.3 \pm 0.8^{\S}$ & $0.4 \pm 0.2$ & $0.3 \pm 0.3$ \\
\hline $\mathrm{Mg}^{2+}-\mathrm{ATPase}$ & $1.6 \pm 0.2$ & $1.1 \pm 0.2^{\S}$ & $9.4 \pm 1.2$ & $1.4 \pm 0.3^{\S}$ \\
\hline Leucineaminopeptidase & $0.5 \pm 0.2$ & $0.6 \pm 0.2$ & $4.7 \pm 0.6$ & $2.0 \pm 0.4^{\S}$ \\
\hline Alkaline phosphatase & $2.1 \pm 0.3$ & $1.4 \pm 0.5^{\S}$ & $14.6 \pm 1.6$ & $6.4 \pm 1.3^{\S}$ \\
\hline$\gamma$-Glutamyltranspeptidase & $1.3 \pm 0.3$ & $1.4 \pm 0.4$ & $5.5 \pm 0.5$ & $2.3 \pm 0.4^{\S}$ \\
\hline
\end{tabular}

* LPM subfractions were isolated $50 \mathrm{~h}$ after sham operation (controls) or bile duct ligation (cholestasis), respectively. All data represent the means $\pm S D$ of single measurements in six separate membrane preparations $(n=6)$.

₹ Total activities in homogenates correspond to $100 \%$.

${ }^{8}$ Significantly different from controls $(P<0.05)$ as determined by paired Student $t$ test. was otherwise similar for blLPM and cLPM subfractions of normal and cholestatic rat livers.

Effect of bile duct ligation on turnover and subcellular distribution of membrane-bound cBSTP. To characterize more specifically the canalicular membrane alterations during extrahepatic obstructive cholestasis we first determined the in vivo degradation half-life of cBSTP by pulse-chase experiments with $\left[{ }^{35}\right.$ S $]$ methionine. As demonstrated in Fig. 1, bile duct ligation decreased the degradation half-life of cBSTP from $65 \pm 5 \mathrm{~h}$ (means $\pm \mathrm{SD}, n=3$ ) in controls to $25 \pm 3 \mathrm{~h}$ in cholestatic animals. In these experiments in vivo-labeled cBSTP was immunoprecipitated from mixed LPM, and the radioactivity in immunoprecipitates was determined by liquid scintillation counting. However, identical results were also obtained if the immunoprecipitates were first subjected to SDS-PAGE and the radioactivity of the $100-\mathrm{kD}$ band then determined by fluorography (data not shown). Thus, the results suggest an increased overall degradation of cBSTP in bile duct-ligated animals. This conclusion was further supported by the presence of decreased amounts of membrane bound cBSTP in the total particulate fraction as well as in mixed LPM and CLPM subfractions of cholestatic livers as determined by rocket immunoelectrophoresis (Fig. 2 and Table III). Thereby, the accelerated breakdown was accompanied by some release of cBSTP into cholestatic bile either in its intact form (mol wt 100,000) or as partially degraded (e.g., deglycosylated) products with apparent molecular weights of $\sim 60,000$ and 50,000 (Fig. 2). Most interestingly, bile duct ligation exerted different effects on cBSTP contents in bILPM and CLPM subfractions. Thus, while in the latter CBSTP was decreased by $\sim 80 \%$, there was a surprising increase of immunoreactive cBSTP by $\sim 55 \%$ in cholestatic blLPM (Table III). Since the extent of this increase cannot be explained by a higher contamination of cholestatic blLPM with canalicular membranes (Tables I and II), the data suggest a cholestasis-induced accumulation of CBSTP at the basolateral plasma membrane. This possibility was further investigated in the intact liver by indirect immunofluorescence techniques. 

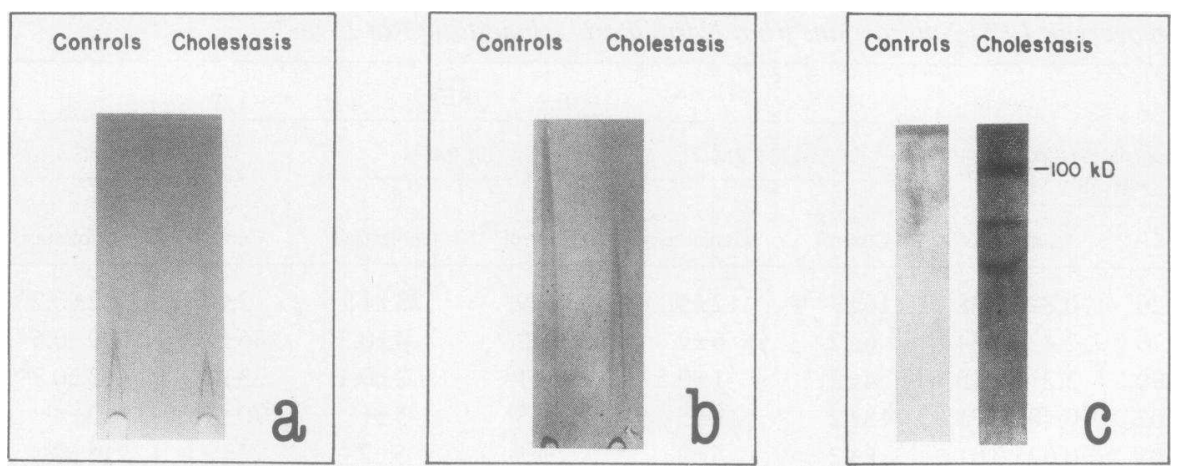

Figure 2. Content of membrane-bound cBSTP in $(a)$ homogenate, $(b)$ cLPM, and $(c)$ bile of normal and cholestatic rat liver. Rats were killed $50 \mathrm{~h}$ after sham operation (controls) or bile duct ligation (cholestasis). The total particulate fraction was sedimented from homogenates at $100,000 \mathrm{~g}_{\text {ave }}$ for $30 \mathrm{~min}$. CLPM were isolated as described in Methods. Aliquots for total particulate fraction ( 200 $\mu \mathrm{g}$ of protein) and CLPM vesicles $(50 \mu \mathrm{g})$ were subjected to rocket immunoelectrophoresis. Bile was collected from the common bile duct and total biliary proteins were precipitated from $50-\mu \mathrm{l}$ bile samples with $20 \mu \mathrm{l}$ of $3 \mathrm{M}$ trichloroacetic acid. The bile proteins were separated by SDS-PAGE and cBSTP-related proteins were detected by immunoblotting.

In vivo distribution of $c B S T P$ in normal and cholestatic rat liver. As demonstrated in Fig. 3, immunoreactive cBSTP was almost exclusively concentrated in bile canaliculi of normal liver. Only weak immunoreactivity was detected at the sinusoidal border of normal hepatocytes. In contrast, $50 \mathrm{~h}$ after bile duct ligation immunoreactivity was reduced at the bile canalicular and significantly increased at the basolateral plasma membrane domains. Identical results were obtained with a more sensitive silver enhanced immunogold labeling technique (Fig. 3, $C$ and $D$ ). In addition, this method demonstrated the presence of numerous immunopositive intracellular spots near the bile canaliculi probably representing cBSTP containing vesicles. These in situ findings corroborate the in vitro studies described above and indicate that portions of cBSTP molecules accumulate in intracellular vesicles and at the basolateral membrane during extrahepatic obstructive cholestasis. To delineate the functional significance of increased basolateral cBSTP content, we next performed taurocholate transport studies in isolated normal and cholestatic CLPM and blLPM vesicles.

Taurocholate transport properties of normal and cholestatic cLPM and blLPM vesicles. It has been previously shown that carrier-mediated taurocholate anion uptake into (36) as well as efflux from $(12,13)$ cLPM vesicles is independent of $\mathrm{Na}^{+}$and

Table III. Contents of cBSTP in Subcellular Fractions Isolated from Normal and Cholestatic Rat Liver*

\begin{tabular}{|c|c|c|}
\hline & \multicolumn{2}{|c|}{ Amount of cBSTP } \\
\hline & Controls & Cholestasis \\
\hline & \multicolumn{2}{|c|}{$\mathrm{pmol} / \mathrm{mg}$ protein } \\
\hline Total particulate fraction ${ }^{\ddagger}$ & $127 \pm 7$ & $77 \pm 5^{\S} \quad(-39 \%)$ \\
\hline Mixed LPM & $498 \pm 9$ & $154 \pm 5^{\S}(-69 \%)$ \\
\hline blLPM & $147 \pm 9$ & $228 \pm 47^{\S}(+55 \%)$ \\
\hline cLPM & $855 \pm 135$ & $191 \pm 73^{\S}(-78 \%)$ \\
\hline
\end{tabular}

* Subcellular fractions were isolated $50 \mathrm{~h}$ after sham operation (controls) or bile duct ligation (cholestasis), respectively. cBSTP was quantitated by rocket immunoelectrophoresis. All data represent the means $\pm \mathrm{SD}$ of single determinations in three separate membrane preparations.

‡ The "total particulate fraction" corresponds to the material sedimented from homogenates at $100,000 \mathrm{~g}_{\text {ave }}$ for $30 \mathrm{~min}$.

${ }^{\S}$ Significantly different from controls as determined by paired Student $t$ test $\left({ }^{\S} P<0.001\right)$. can be stimulated by intravesicular positive or negative $\mathrm{K}^{+}$ diffusion potentials, respectively. Therefore, we first compared the effects of an inside negative $\mathrm{K}^{+}$diffusion potential on taurocholate efflux from normal and cholestatic cLPM vesicles. As shown in Fig. 4, cLPM vesicles from bile duct-ligated $(50 \mathrm{~h})$ animals exhibited markedly reduced potential-sensitive taurocholate efflux as compared with cLPM vesicles from shamoperated controls. In contrast, an intravesicular positive $\mathrm{K}^{+}$ diffusion potential markedly stimulated $\mathrm{Na}^{+}$-independent taurocholate uptake into cholestatic blLPM vesicles, whereas it exerted only minimal effects on early taurocholate uptake rates in blLPM vesicles of normal liver (Fig. 5). This increased electrogenic taurocholate uptake into cholestatic blLPM could quantitatively not be accounted for by increased microsomal contamination (Table I), as verified in separate experiments with microsomes isolated from normal and cholestatic livers (data not shown). Thus, the above demonstrated basolateral accumulation of immunoreactive cBSTP during obstructive cholestasis (Table III and Fig. 3) was functionally paralleled by increased canalicular taurocholate transport properties in blLPM vesicles indicating basolateral accumulation of functionally intact cBSTP in cholestatic hepatocytes. For control, we finally also determined $\mathrm{Na}^{+}$-gradient driven, secondary active taurocholate uptake, a typical basolateral function of normal hepatocytes (ref. 12, 37-39), in blLPM vesicles of normal and cholestatic (50-h bile duct ligation) liver. In these experiments taurocholate uptake was determined in the presence of out to in $\mathrm{NaCl}$ or $\mathrm{KCl}$ gradiens (Fig. 6). Thereby, the formation of an inside positive $\mathrm{K}^{+}$diffusion potential was prevented by not treating the vesicles with valinomycin and by using the permeant anion chloride rather than gluconate. The data in Fig. 6 demonstrate that an inwardly directed $\mathrm{NaCl}$, but not $\mathrm{KCl}$, gradient induced a similar transient intravesicular accumulation of $\left[{ }^{3} \mathrm{H}\right]$ taurocholate (overshoot) in both blLPM preparations. Together with the unaltered $\mathrm{Na}^{+} \mathrm{K}^{+} \mathrm{ATPase}$ activity (Table I), these results suggest that bile duct ligation for up to $50 \mathrm{~h}$ does not affect sodium-dependent uptake of bile salts into rat hepatocytes.

\section{Discussion}

In the present study we studied the effects of extrahepatic mechanical obstruction of the common bile duct on the bile salt secretory polarity of rat hepatocytes. Specifically, the fate and functional activity of the CBSTP were investigated in intact liver as well as isolated basolateral (blLPM) and canalicular 

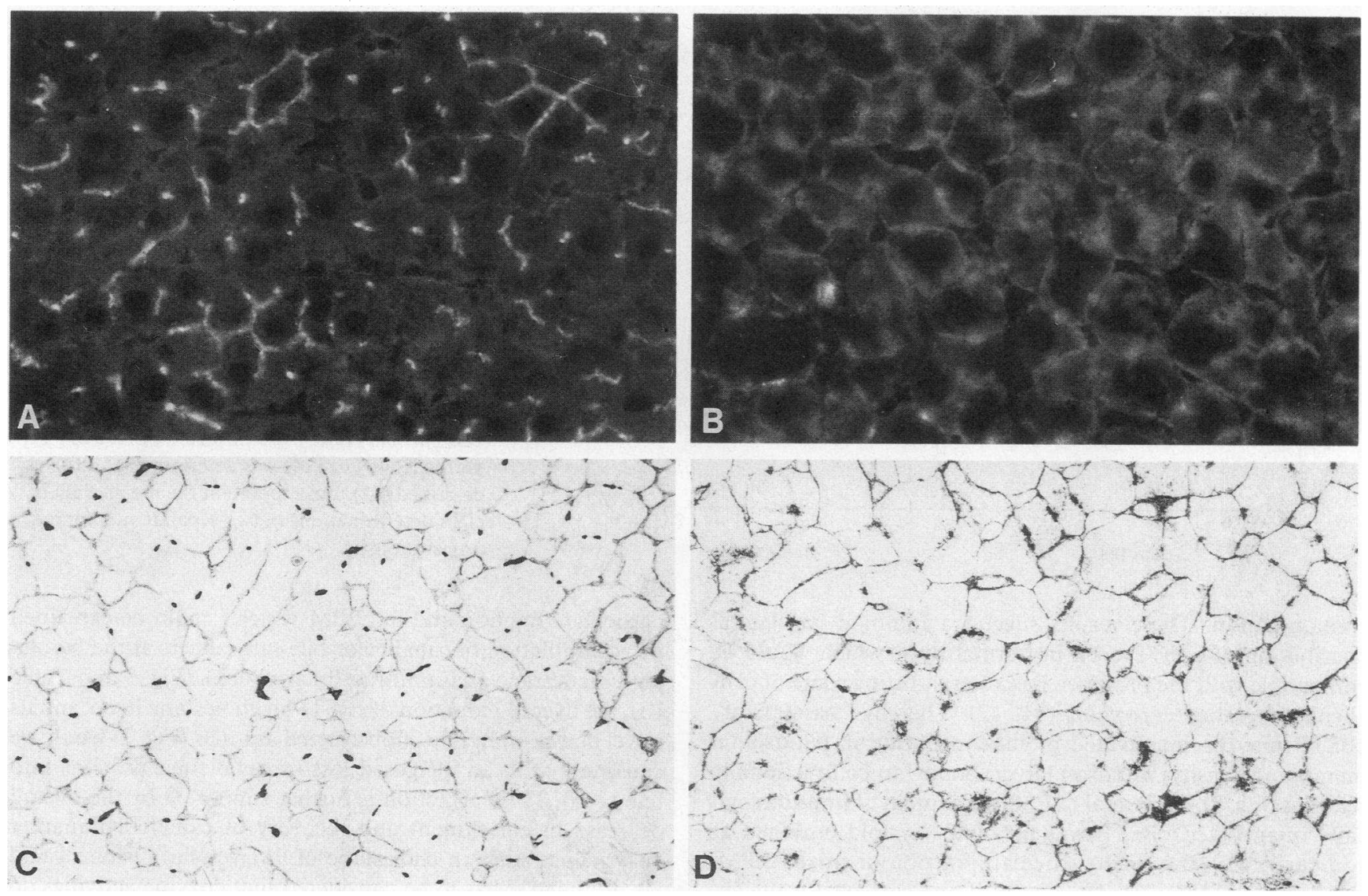

Figure 3. In situ immunolocalization of cBSTP in $(A$ and $C)$ normal and $(B$ and $D)$ cholestatic rat liver. $(A$ and $B)$ Immunofluorescence; $(C$ and $D$ ) silver enhanced immunogold labeling. Cholestasis was induced by bile duct ligation for $50 \mathrm{~h} . \times 400$.

(cLPM) membrane vesicles. The findings demonstrate both an increased degradation and loss of cBSTP into bile (Figs. 1 and 2; Table III) as well as an accumulation of functionally active cBSTP at the basolateral membrane domain of hepatocytes (Figs. 3-5; Table III) in bile duct-ligated animals. Although previously suggested on indirect morphological grounds (2, 8-11), the present study represents the first direct demonstration of a reversed bile salt secretory polarity in cholestatic hepatocytes. Furthermore, in view of similar $\mathrm{Na}^{+}$-dependent taurocholate uptake values in bILPM vesicles of normal and cholestatic livers (Fig. 6), our results support the hypothesis (2) that bile salts and possibly also other bile constituents can regurgitate into blood plasma without being first secreted into bile canaliculi and obstructed bile ducts (Fig. 7).

In normal liver cBSTP is almost exclusively distributed to the canalicular membrane of hepatocytes (Fig. 3). However, faint immunolabel is consistently found on the basolateral membrane domain as well (Fig. 3 and reference 40) indicating that the relatively high specific cBSTP content of "normal" blLPM (Table III) did not solely result from canalicular cross-

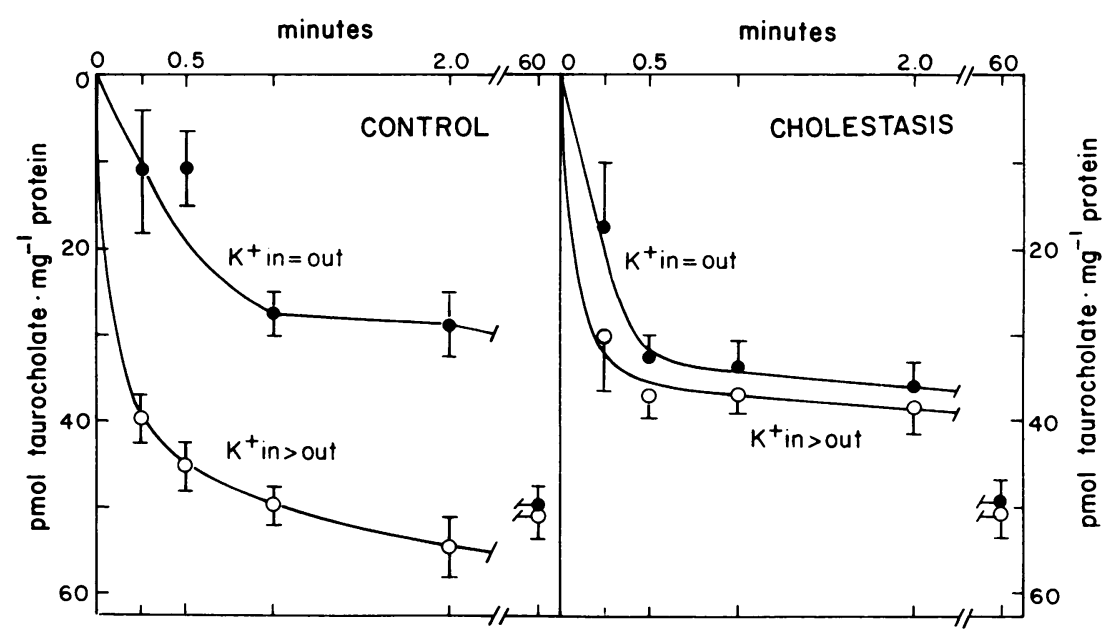

Figure 4. Potential-sensitive efflux of taurocholate from CLPM vesicles of normal and cholestatic rat liver. Animals were killed $50 \mathrm{~h}$ after sham operation (controls) or bile duct ligation (cholestasis). Isolated CLPM vesicles were resuspended in a medium containing $100 \mathrm{mM} \mathrm{K}^{+}, 100 \mathrm{mM}$ sucrose, $0.2 \mathrm{mM} \mathrm{Ca}^{2+}, 5 \mathrm{mM} \mathrm{Mg}^{2+}, 110.4 \mathrm{mM}$ gluconate, and $20 \mathrm{mM}$ Hepes/Tris, adjusted to $\mathrm{pH}$ 7.5. The vesicles were preloaded with $10 \mu \mathrm{M}\left[{ }^{3} \mathrm{H}\right]-$ taurocholate, treated with valinomycin $(10 \mu \mathrm{g} / \mathrm{mg}$ protein) and $10-\mu \mathrm{l}$ aliquots (100 $\mu \mathrm{g}$ of protein) incubated in $190 \mu \mathrm{l}$ of incubation medium containing $100 \mathrm{mM}$ sucrose, $0.2 \mathrm{mM} \mathrm{Ca}^{2+}, 5 \mathrm{mM} \mathrm{Mg}^{2+}$, $110.4 \mathrm{mM}$ gluconate, $20 \mathrm{mM}$ Hepes/Tris, $\mathrm{pH} 7.5$, and either $(\bullet)$ or $(0) 100 \mathrm{mM}$ tetramethylammonium. Tracer taurocholate efflux was determined at $25^{\circ} \mathrm{C}$ as described $(12,13)$. Data represent the means \pm SD of eight determinations in two separate membrane preparations. 


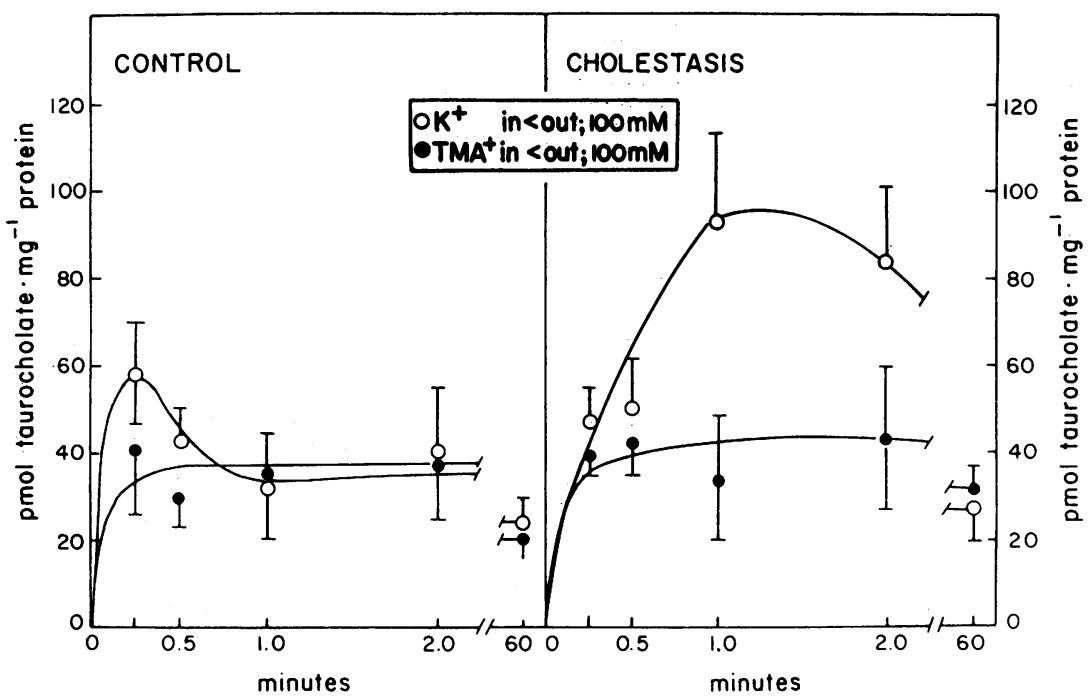

Figure 5. Electronic $\mathrm{Na}^{+}$-independent taurocholate uptake in blLPM vesicles of normal and cholestatic rat liver. Rats were killed $50 \mathrm{~h}$ after shamoperation (controls) or bile duct ligation (cholestasis). Isolated blLPM vesicles were resuspended in a medium containing $250 \mathrm{mM}$ sucrose, $0.2 \mathrm{mM}$ $\mathrm{Ca}^{2+}, 5 \mathrm{mM} \mathrm{Mg}{ }^{2+}, 10.4 \mathrm{mM}$ gluconate, and 10 $\mathrm{mM}$ Hepes/Tris, adjusted to $\mathrm{pH}$ 7.5. The vesicles were treated with valinomycin $(10 \mu \mathrm{g} / \mathrm{mg}$ protein) and $20-\mu \mathrm{l}$ aliquots ( $50 \mu \mathrm{g}$ of protein) incubated in $80 \mu$ l of incubation medium containing $50 \mathrm{mM}$ sucrose, $0.2 \mathrm{mM} \mathrm{Ca}^{2+}, 5 \mathrm{mM} \mathrm{Mg}^{2+}, 110.4 \mathrm{mM}$ $\mathrm{Cl}^{-}, 10 \mathrm{mM}$ Hepes/Tris, pH 7.5, and either (•) $100 \mathrm{mM} \mathrm{Na}^{+}$or (0) $100 \mathrm{mM} \mathrm{K}$. Uptake of $\left[{ }^{3} \mathrm{H}\right]-$ taurocholate $(10 \mu \mathrm{M})$ was determined at $25^{\circ} \mathrm{C}$ as described (12). Data represent the means $\pm \mathrm{SD}$ of eight determinations in two separate membrane preparations. contamination. These results suggest a minimal basolateral distribution of CBSTP even in normal liver, which would be compatible with the proposed basolateral sorting route of canalicular membrane proteins $(41,42)$. Thereby "basolateral" cBSTP may be inactivated or its concentration (sinusoidal membrane density) in normal liver too low to be functionally relevant (Fig. 5). In normal cLPM, the content of immunologically quantitated cBSTP was 6.8- and 1.7-fold enriched as compared with the total particulate fraction or mixed LPM, respectively (Table III). Thus, even if one corrects for the absence of soluble proteins in the total particulate fraction $(50 \%$ of homogenate), the cLPM enrichment factors for CBSTP were considerably lower than those for the canalicular marker enzyme activities (Table I). The reasons for these discrepancies are unknown at present, but a possibility may be that CBSTP exhibits significant additional subcellular localization such as for example in endoplasmic reticulum $(43,44)$ and/or in Golgi complex (45).

Bile duct ligation resulted in a $60 \%$ decrease of the in vivo half-life of cBSTP immunoprecipitated from mixed LPM (Fig. 1) and in an overall reduction of membrane bound cBSTP by $39 \%$ in homogenates (total particulate fraction) and by $78 \%$ in cLPM vesicles (Fig. 2 and Table III). Simultaneously, the electrogenic taurocholate efflux was reduced by $>70 \%$ in cholestatic cLPM vesicles compared with controls (Fig. 4). Although the discrepancy between the reduction of CBSTP in the total particulate fraction and in CLPM vesicles could be explained by accumulation of canalicular bile salt carriers at the basolateral membrane and in intracellular vesicles (Fig. 3 and Table III), the overall reduction of CBSTP in cholestatic livers and its novel detection in bile of obstructed animals (Fig. 2) would be consistent with an increased loss of canalicular proteins into bile (1-5). This suggestion is further supported by the overall decrease in enrichment and recovery of canalicular marker enzyme activities in cholestatic cLPM vesicles (Tables I and II), although it has to be considered that enzyme activities do not recessary reflect amounts of enzyme protein. Nevertheless, the findings are in agreement with the reported preferential canalicular loss of intramembrane particles in freeze fracture replicas during bile duct obstruction (46). Interestingly, the $\sim 80 \%$ reduction in content and functional activity of cBSTP in cholestatic cLPM vesicles (Table III and Fig. 4) was associated with a minor decrease in the recovery of cLPM protein $(-30 \%)$ and with a $50-60 \%$ reduction in the activity and recovery of the canalicular membrane enzymes leucineaminopeptidase and $\gamma$-glutamyltranspeptidase (Tables I and II). Because of the low overall cLPM recovery it remains unclear whether these differences resulted from selection of a special subpopulation of cLPM vesicles during subcellular fractionation, or whether they rather reflect a preferential loss in vivo of cBSTP-enriched canalicular membrane domains. Although the latter possibility would be compatible with the reported

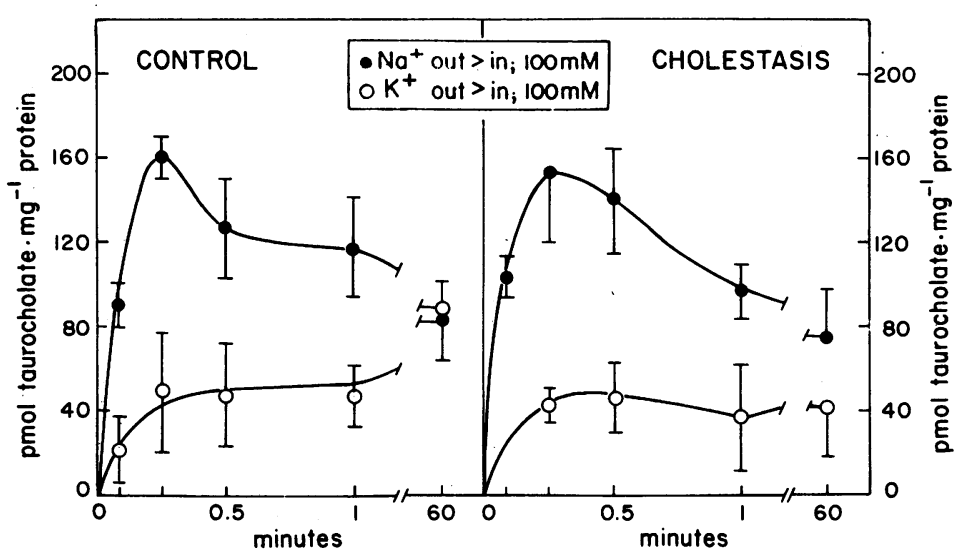

Figure 6. $\mathrm{Na}^{+}$gradient-dependent taurocholate uptake into bILPM vesicles or normal and cholestatic rat liver. Rats were killed $50 \mathrm{~h}$ after sham operation (controls) or bile duct ligation (cholestasis). Isolated blLPM vesicles were resuspended in a medium containing $250 \mathrm{mM}$ sucrose, $0.2 \mathrm{mM}$ $\mathrm{Ca}^{2+}, 5 \mathrm{mM} \mathrm{Mg}^{2+}, 10.4 \mathrm{mM}$ gluconate, and $10 \mathrm{mM}$ Hepes/ Tris, adjusted to $\mathrm{pH}$ 7.5. Aliquots of $20 \mu \mathrm{l}$ ( $50 \mu \mathrm{g}$ of protein) were incubated in $80 \mu \mathrm{l}$ of incubation medium containing $50 \mathrm{mM}$ sucrose, $0.2 \mathrm{mM} \mathrm{Ca}^{2+}, 5 \mathrm{mM} \mathrm{Mg}{ }^{2+}, 110.4 \mathrm{mM} \mathrm{Cl}^{-}$, $10 \mathrm{mM}$ Hepes/Tris, pH 7.5, and either (•) $100 \mathrm{mM} \mathrm{Na}^{+}$or (0) $100 \mathrm{mM} \mathrm{K}^{+}$. Uptake of $\left[{ }^{3} \mathrm{H}\right]$ taurocholate $(10 \mu \mathrm{M})$ was determined at $25^{\circ} \mathrm{C}$ as described (12). Data represent the means \pm SD of eight determinations in two separate membrane preparations. 


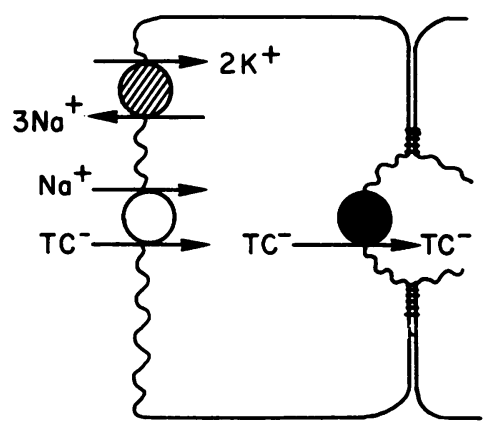

Normal Liver

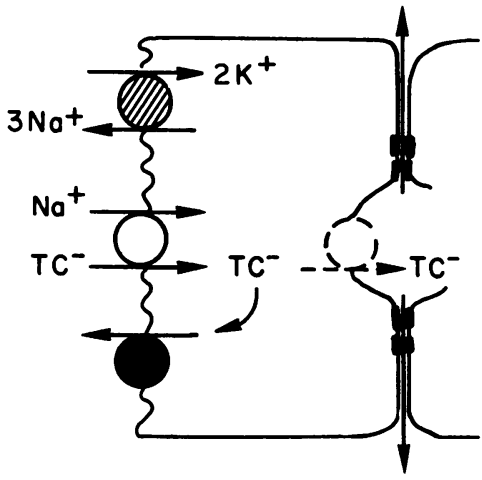

Obstructive Cholestasis
Figure 7. Schematic illustration of the effect of obstructive cholestatis on the hepatocellular surface distribution of cBSTP. For explanations see text. TC $^{-}$, taurocholate. reduction of bile salt secretion shortly after relief of prolonged bile duct obstruction (47), a decreased amount of cBSTP within the canalicular membrane could obviously not explain the observation of a normal taurocholate transport maximum after relief of a 7-d bile duct-ligated period (48). However, decreased hepatocellular secretion of taurocholate during biliary obstruction might be a transient phenomenon as recently evidenced by a histoautoradiographic study in rat liver (49). Clearly further studies are warranted to investigate whether reestablishment of hepatocellular bile acid secretion during and after prolonged biliary obstruction quantitatively correlates with a concomitant canalicular increase of functionally active cBSTP.

In addition to increased degradation, bile duct ligation also resulted in an accumulation of cBSTP within the basolateral border of hepatocytes as evidenced in both intact liver (Fig. 3) as well as isolated blLPM vesicles (Table III). In the latter, the $55 \%$ increase in membrane-associated cBSTP was paralleled by a similar increase (between $50 \%$ and $100 \%$ ) in potential sensitive taurocholate anion uptake (Fig. 5). These findings indicate basolateral accumulation of functionally active canalicular bile salt carriers in cholestatic hepatocytes rather than an increased contamination of "cholestatic" blLPM vesicles with canalicular membranes, since the relative enrichments of canalicular marker enzyme activities remained similar in blLPM vesicles of normal and cholestatic liver (Table I). Thus, the results provide direct evidence for structural and functional reversal of the bile salt secretory polarity in hepatocytes during extrahepatic cholestasis, thereby corroborating previous enzymatic, histochemical and immunofluorescence studies with various canalicular enzymes $(2,8-10)$ and with different domain specific antigens of unknown functions (11), respectively. These earlier observations indicate that loss of the hepatocellular surface polarization during biliary obstruction is a general phenomenon that affects a variety of both canalicular (8-11) and sinusoidal (11) domain specific proteins. The present study provides no conclusive evidence with respect to an altered polarization of plasma membrane constituents other than cBSTP in cholestatic hepatocytes, although in cholestatic blLPM canalicular marker enzyme activities were considerably less decreased compared with cholestatic cLPM or even unaltered when compared with normal blLPM (Tables I and II). Thus, differential cholestatic effects on various enzymes (Tables I and references 9, 34, 35, and 50) and/or the low overall recovery of isolated basolateral and canalicular membranes (Table II) might have masked the clear detection of a simultaneous basolateral accumulation of the respective marker enzyme activities. Yet, the unaltered $\mathrm{Na}^{+} \mathrm{K}^{+} \mathrm{ATPase}$ activity (Table I and reference 9 ) and the normal $\mathrm{Na}^{+}$-dependent taurocholate uptake (Fig. 6) in cholestatic blLPM vesicles strongly indicate that essential basolateral membrane functions remain intact during the initial periode of obstructive cholestasis. Hence, as schematically outlined in Fig. 7, the basolateral membrane could exhibit normal $\mathrm{Na}^{+}$-dependent bile salt uptake as well as CBSTP-mediated potential sensitive bile salt anion efflux in cholestatic hepatocytes. The latter process might protect hepatocytes from too high an accumulation of toxic bile salts within the cell interior and could temporarily well sustain high bile salt concentrations in blood plasma even after relief of the biliary obstruction (48).

Several mechanisms could potentially explain the basolateral accumulation of cBSTP in hepatocytes of bile duct-ligated animals. First, cBSTP could have diffused in the plane of the membrane across altered tight junctions (51-53), although it should be realized that passage of proteins across tight junctions has never been conclusively demonstrated. Secondly, cBSTP could have reached the basolateral membrane transcellularly via retrograde diacytosis $(6,7)$. Thirdly, newly synthesized cBSTP could have been missorted in the Golgi apparatus (54) followed by incorrect insertion into the plasma membrane. Fourthly, based on the recent suggestion that canalicular membrane biogenesis first requires insertion of integral canalicular membrane proteins into the basolateral plasma membrane followed by their selective endocytosis and transport to the canalicular domain $(41,42)$ obstructive cholestasis could have selectively blocked the basolateral-to-canalicular movement of cBSTP by affecting some form of vesiclemediated transcytosis. Whatever the exact mechanism, the evidence for the presence of cBSTP containing intracellular vesicles suggests that a vesicle-mediated transport pathway is disrupted during obstructive cholestasis. Clearly further experimentation is required to delineate the exact mechanisms involved in the establishment of the reversed bile salt secretory polarity in cholestatic hepatocytes.

Note added in proof. Recent studies performed to further characterize cBSTP provided evidence that our polyclonal antiserum recognizes at least three different $100-\mathrm{kD}$ canalicular proteins. Since it is unclear at present which of these protein(s) is (are) specifically involved in canalicular secretion of bile acids, the reported immunological studies might quantitatively be overestimated. However, these limitations should not alter the main conclusions of the present work regarding the reversal of the bile salt secretory polarity of hepatocytes during extrahepatic obstructive cholestasis. 


\section{Acknowledgments}

We thank E. Zingg, C. Champion, and E. Fahrnbühl for excellent technical assistance, H. J. Stöcklin for photography, and K. Köhler for careful typing of the manuscript.

This study was supported by the Swiss National Science Foundation (grants 3.983.0.84 and 3.992.0.87), the Sandoz-Stiftung zur Förderung der Medizinisch-Biologischen Wissenschaften, and the Roche Research Foundation.

\section{References}

1. Duffy, M. C., and J. L. Boyer. 1986. Pathophysiology of intrahepatic cholestasis and biliary obstruction. In Bile Pigments and Jaundice. Molecular, Metabolic and Medical Aspects. J. D. Ostrow, editor. Marcel Dekker, Inc., New York. 333-372.

2. Desmet, V. J. 1986. Current problems in diagnosis of biliary disease and cholestasis. Semin. Liver Dis. 6:233-245.

3. Phillips, M. J., S. Poucell, and M. Oda. 1986. Biology of disease: mechanisms of cholestasis. Lab. Invest. 54:593-608.

4. Reichen, J., and R. R. Simon. 1988. Cholestasis. In The Liver Biology and Pathobiology. I. M. Arias, W. B. Jakoby, H. Popper, D. Schachter, and D. A. Shafritz, editors. Raven Press, New York. 1105-1124.

5. Jones, A. L., D. L. Schmucker, J. S. Mooney, R. D. Adler, and R. T. Ockner. 1976. Morphometric analysis of rat hepatocytes after total biliary obstruction. Gastroenterology. 71:1050-1060.

6. Felker, T. E., R. L. Hamilton, and R. J. Havel. 1978. Secretion of lipoprotein-X by perfused livers of rats with cholestasis. Proc. Natl. Acad. Sci. USA. 75:3459-3463.

7. Jones, A. L., G. T. Hradek, D. L. Schmucker, and B. J. Underdown. 1984. The fate of polymeric and secretory immunoglobulin $A$ after retrograde infusion into the common bile duct in rats. Hepatology (Baltimore). 4:1173-1183.

8. Desmet, V. J. 1972. Morphologic and histochemical aspects of cholestasis. Prog. Liver Dis. 4:97-132.

9. Toda, G., M. Kako, H. Oka, T. Oka, and Y. Ikeda. 1978. Uneven distribution of enzymatic alterations on the liver cell surface in experimental extrahepatic cholestasis of rat. Exp. Mol. Pathol. 28:1024.

10. Busachi, C., J. Mebis, L. Broeckaert, and V. Desmet. 1981. Histochemistry of gamma-glutamyltranspeptidase in human liver biopsies. Pathol. Res. Pract. 172:99-108.

11. Durand-Schneider, A. M., M. Maurice, M. Dumont, and G. Feldmann. 1987. Effect of colchicine and phalloidin on the distribution of three plasma membrane antigens in rat hepatocytes: comparison with bile duct ligation. Hepatology (Baltimore). 7:1239-1248.

12. Meier, P. J., A. St. Meier-Abt, C. Barrett, and J. L. Boyer. 1984. Mechanisms of taurocholate transport in canalicular and basolateral rat liver plasma membrane vesicles: evidence for an electrogenic canalicular organic anion carrier. J. Biol. Chem. 259:10614-10622.

13. Meier, P. J., A. St. Meier-Abt, and J. L. Boyer. 1987. Properties of the canalicular bile acid transport system in rat liver. Biochem. $J$. 242:465-469.

14. Fricker, G., S. Schneider, W. Gerok, and G. Kurz. 1987. Identification of different transport systems for bile salts in sinusoidal and canalicular domains of hepatocytes. Biol. Chem. Hoppe-Seyler. 368:1143-1150.

15. Ruetz, S., G. Fricker, G. Hugentobler, K. Winterhalter, G. Kurz, and P. J. Meier. 1987. Isolation and characterization of the putative canalicular bile salt transport system of rat liver. J. Biol. Chem. 262:11324-11330.

16. Ruetz, S., G. Hugentobler, and P. J. Meier. 1988. Functional reconstitution of the canalicular bile salt transport system of rat liver. Proc. Natl. Acad. Sci. USA. 85:6147-6151.

17. Meier, P. J., E. S. Sztul, A. Reuben, and J. L. Boyer. 1984 Structural and functional polarity of canalicular and basolateral plasma membrane vesicles isolated in high yield from rat liver. J. Cell Biol. 98:991-1000.

18. Bradford, M. M. 1976. A rapid and sensitive method for the quantitation of microgram quantities of protein utilizing the principle of protein dye binding. Anal. Biochem. 72:248-254.

19. Scharschmidt, B. F., E. B. Keeffe, N. M. Blankenship, and R. K. Ockner. 1979. Validation of a recording spectrophotometric method for measurement of membrane associated $\mathrm{Mg}^{++}$and $\mathrm{Na}^{+} \mathrm{K}^{+}$. ATPase activity. J. Lab. Clin. Med. 93:790-799.

20. Goldbarg, J. A., and A. M. Rutenburg. 1958. The colometric determination of leucine aminopeptidase in urine and serum of normal subjects and patients with cancer and other diseases. Cancer (Phila.). 2:283-291.

21. Keeffe, E. B., B. F. Scharschmidt, N. M. Blankenship, and R. K. Ockner. 1979. Studies of relationships among bile flow, liver plasma membrane $\mathrm{Na}^{+} \mathrm{K}^{+}$-ATPase, and membrane microviscosity in the rat. J. Clin. Invest. 64:1590-1598.

22. Orlowski, M., and A. Meister. 1963. $\gamma$-Glutamyl-p-nitroanilide: a new convenient substrate for determination and study of $\mathrm{L}-$ and D- $\gamma$-glutamyltranspeptidase activities. Biochim. Biophys. Acta. 73:676-679.

23. Sottocasa, G. L., B. Kuylenstierna, L. Ernster, and A. Berstrand. 1967. An electron-transport system associated with the outer membrane of liver mitochondria. J. Cell Biol. 32:415-438.

24. Rothstein, T. L., and J. J. Blum. 1973. Lysosomal physiology in tetrahymena. I. Effect of glucose, acetate, pyruvate and carmine on intracellular content and extracellular release of three acid hydrolases. J. Cell Biol. 57:630-641.

25. Fleischer, B., and M. Smigel. 1978. Solubilization and properties of galactosyltransferase and sulfotranssferase activities of Golgi membranes in Triton X-100. J. Biol. Chem. 253:1632-1638.

26. Laemmli, U. K. 1970. Cleavage of structural proteins during the assembly of the head of bacteriophage $\mathrm{T}_{4}$. Nature (Lond.). 227:680-685.

27. Steck, G., P. Leuthard, and R. P. Bürk. 1980. Detection of basic proteins and low molecular weight peptides in polyacrylamide gels by formaldehyde. Anal. Biochem. 107:21-24.

28. Merril, C. R., M. L. Dunaum, and D. Goldman. 1981. A rapid sensitive silver stain for polypeptides in polyacrylamide gels. Anal Biochem. 110:201-207.

29. Pickett, C. B., R. L. Jeter, J. Morin, and A. Y. H. Lu. 1981 Electroimmunochemical quantitation of cytochrome P-450, cytochrome P-448, and epoxide hydrolase in rat liver microsomes. $J$. Biol. Chem. 256:8815-8820.

30. Blitzer, B. L., and J. L. Boyer. 1978. Cytochemical localization of $\mathrm{Na}^{+} \mathrm{K}^{+}$-ATPase in the rat hepatocytes. J. Clin. Invest. 62:11041108.

31. Latham, P. S., and M. Kashgarian. 1979. The ultrastructural localization of transport ATPase in the rat liver at nonbile canalicular plasma membranes. Gastroenterology. 76:988-996.

32. Boyer, J. L., R. M. Allen, and O. Ch. Ng. 1983. Biochemical separation of $\mathrm{Na}^{+} \mathrm{K}^{+}$-ATPase from a "purified" light density, "canalicular"-enriched plasma membrane fraction from rat liver. Hepatology (Baltimore). 3:18-28.

33. Sztul, E. S., D. Biemesderfer, M. J. Caplan, M. Kashgarian, and J. L. Boyer. 1987. Localization of $\mathrm{Na}^{+}, \mathrm{K}^{+} \mathrm{ATPase} \alpha$-subunit to the sinusoidal and lateral but not canalicular membranes of rat hepatocytes. J. Cell Biol. 104:1239-1248.

34. Kaplan, M. M., A. Ohkubo, E. G. Quaroni, and D. Sze-Tu. 1983. Increased synthesis of rat liver alkaline phosphatase by bile duct ligation. Hepatology (Baltimore). 3:368-376.

35. Seetharam, S., N. L. Sussman, T. Komoda, and D. H. Alpers. 1986. The mechanism of elevated alkaline phosphatase activity after bile duct ligation in the rat. Hepatology (Baltimore). 6:374-380.

36. Inoue, M., R. Kinne, T. Tran, and I. M. Arias. 1984. Taurocholate transport by rat liver canalicular membrane vesicles: evidence for the presence of a Na-independent transport system. J. Clin. Invest. 73:659-663. 
37. Inoue, M., R. Kinne, T. Tran, and I. M. Arias. 1982. Taurocholate transport by rat liver sinusoidal membrane vesicles: evidence for sodium cotransport. Hepatology (Baltimore). 2:572-579.

38. Blitzer, B. L., and C. B. Donovan. 1984. A new method for the rapid isolation of plasma membrane vesicles from rat liver: characterization, validation, and bile acid transport studies. J. Biol. Chem. 259:9295-9301.

39. Berk, P. D., B. J. Potter, and W. Stremmel. 1987. Role of plasma membrane ligand-binding proteins in the hepatocellular uptake of albumin-bound organic anions. Hepatology (Baltimore). 7:165-176.

40. Meier, P. J., S. Ruetz, G. Fricker, and L. Landman. 1987. Isolation and characterization of a canalicular bile salt binding polypeptide of rat liver. In Bile Acids and the Liver. G. Paumgartner, A. Stiehl, and W. Gerok, editors. MTP Press Ltd., Lancaster, England. 137-142.

41. Bartles, J. R., H. M. Feracci, B. Stieger, and A. L. Hubbard. 1987. Biogenesis of the rat hepatocyte plasma membrane in vivo: comparison of the pathways taken by apical and basolateral proteins using subcellular fractionation. J. Cell Biol. 105:1241-1251.

42. Bartles, J. R., and A. L. Hubbard. 1988. Plasma membrane protein sorting in epithelial cells: do secretory pathways hold the key? Trends Biochem. Sci. 13:181-184.

43. Simion, F. A., B. Fleischer, and S. Fleischer. 1984. Two distinct mechanisms for taurocholate uptake in subcellular fractions from rat liver. J. Biol. Chem. 259:10814-10822.

44. Reuben, A., and R. M. Allen. 1988. Taurocholate (TC) transport by rat liver microsomes. Gastroenterology. 94:A 584. (Abstr.)

45. Lamri, Y., A. Roda, M. Dumont, G. Feldmann, and S. Erlinger. 1988. Immunoperoxidase localization of bile salts in rat liver cells: evidence for a role of the Golgi apparatus in bile salt transport. $J$. Clin. Invest. 82:1173-1182.
46. Robenek, H., V. Grosser, G. Kolde, and H. Themann. 1980. Freeze-fracture study of morphology of cell membranes in hepatocytes following extrahepatic cholestasis. Pathol. Res. Pract. 167:322-334.

47. Kountouras, J., S. McKavanagh, M. Burmicky, and B. H. Billing. 1987. The effect of secretion on bile flow and bile acid and bilirubin excretion following relief of prolonged bile duct obstruction in the rat. J. Hepatol. 4:198-205.

48. Accantino, L., A. Conteras, S. Fernandez, and C. Quintana. 1979. The effect of complete biliary obstruction on bile flow and bile acid excretion: postcholestatic choleresis in the rat. J. Lab. Clin. Med. 93:706-717.

49. Buscher, H. P., C. Mittenberger, S. MacNelly, and W. Gerok. 1988. Reestablishment of hepatobiliary taurocholate transport after bile duct ligation: a histoautoradiographic study in rats. J. Hepatol. 7(Suppl. 1):S15. (Abstr.)

50. Misumi, Y., K. Tashiro, M. Hattori, Y. Sakaki, and Y. Ikehara. 1988. Primary structure of rat liver alkaline phosphatase deduced from its cDNA. Biochem. J. 149:661-668.

51. Metz, J., A. Aoki, M. Merio, and W. G. Forssmann. 1977. Morphological alterations and functional changes of interhepatocellular junctions induced by bile duct ligation. Cell Tissue Res. 182:299310.

52. De Vos, R., and J. Desmet. 1978. Morphologic changes of the junctional complex of the hepatocytes in rat liver after bile duct ligation. Br. J. Exp. Pathol. 59:220-227.

53. Robenek, H., J. Herwig, and H. Themann. 1980. The morphologic characteristics of intercellular junctions between normal human liver cells and cells from patients with extrahepatic cholestasis. Am. J. Pathol. 100:93-103.

54. Farquhar, M. J. 1985. Progress in unraveling pathways of Golgi traffic. Annu. Rev. Cell Biol. 1:447-488. 